\title{
CORRIGENDUM
}

\section{VEGF receptors on chronic lymphocytic leukemia (CLL) B cells interact with STAT 1 and 3: implication for apoptosis resistance}

YK Lee, TD Shanafelt, ND Bone, AK Strege, DF Jelinek and NE Kay

Leukemia (2010) 24, 908; doi:10.1038/leu.2010.28

Correction to: Leukemia (2005) 19, 513-523; doi:10.1038/ sj.leu. 2403667

Since the publication of this paper, the authors would like to withdraw Figures $7 \mathrm{a}$ and $\mathrm{b}$ from their article. Due to concern of possible research misconduct, the authors of this paper self-initiated an external research review. The investigation committee report to the Federal Office of Research Integrity concluded that the two figures were altered, and did not reflect the experimental results.

The authors believe the remaining data, discussion, and conclusions are valid and apologize for any inconvenience caused. 